\title{
Empirical evaluation of educational interactive systems
}

\author{
Francisco José García-Peñalvo ${ }^{1} \cdot$ Lourdes Moreno López ${ }^{2} \cdot$ Ma $^{a}$ Cruz Sánchez-Gómez ${ }^{3}$
}

Published online: 13 August 2018

(c) Springer Nature B.V. 2018

\begin{abstract}
Educational software systems are usually highly interactive systems that needs to be evaluated from two different perspectives, first as interactive software, mainly using usability and accessibility approaches, and second as an educational product that needs to be evaluated from its learning impact. The empirical evaluation methods may be quantitative, with a more deductive reasoning, or qualitative, with a more inductive reasoning, oriented, however mixed approaches have been used extensively because they combine the both main methods with a more pragmatic knowledge focusing on knowing the consequences or solving problems. The empirical evaluation of interactive educational software due to its own characteristics requires a mixed approach typically. This special issue is devoted to identify, share and valorise best practices and experiences, with a very solid modelling background, that are focused on the empirical evaluation of educational interactive systems with a special emphasis on mixed quantitative and qualitative approaches.
\end{abstract}

Keywords Educational interactive software - Empirical evaluation - Usability studies . User experience $\cdot$ Mixed methods

\section{Introduction}

Educational software products usually have an interactive dimension that should be evaluated by the way of the user experience, ease of use and perceived usefulness, this means a qualitative approach (Sánchez-Prieto et al. 2016, 2017). But, the educational character of these software systems should be evaluated to demonstrate their learning impact, mostly

Francisco José García-Peñalvo

fgarcia@usal.es

Lourdes Moreno López

1moreno@inf.uc3m.es

Ma Cruz Sánchez-Gómez

mcsago@usal.es

1 Computer Science Department, Research Institute for Educational Sciences, GRIAL Research

Group, University of Salamanca, Salamanca, Spain

2 Computer Science Department, Universidad Carlos III de Madrid, Madrid, Spain

3 Didactics, Organization and Research Methods Department, Faculty of Education, University of Salamanca, Salamanca, Spain 
with a quantitative orientation (García-Peñalvo and Seoane-Pardo 2015). Thus, educational software is a perfect candidate to be evaluated using a mixed perspective, combining both qualitative and quantitative dimensions and methods, especially with using the so-called mixed methods.

Research in educational technologies requires validating the engineering constructs with Social Sciences and Educational Research methods (Cohen et al. 2018).

In Social Sciences, two main theoretical perspectives have prevailed until a few years ago (Bruyn 1966). The first, positivism, whose purpose is to look for the facts or causes of social phenomena independently of the subjective states of individuals. And, the second, constructivism, whose objective is to understand social phenomena from the perspective of the actor.

The quantitative methodology is usually associated with the positivism that underlies Durkheim's (1982) conception of the Social Sciences, according to which (a) the facts are considered as things and should be studied in the way natural sciences do; (b) the results must be formulated in the form of laws or generalizations similar to those of the Natural Sciences; (c) value neutrality or regulation.

However, for Weber (Eliaeson 2000), nevertheless, to understand, is to apprehend the internal meaning of the social phenomena. The understanding for Weber is to grasp the meaning that each actor attributes to his own behaviour (subjective senses).

This need for interpretation, which cannot be carried out without the mediation of language and without considering the internal states of the subject, has led to the qualification of this perspective as qualitative. In the background lies a repudiation to apply the same methodology to the natural and social world. The natural world is explained and the social world is understood.

From a position of harmony, the possibilities of each methodology are also valued, respecting their respective contributions. This does not imply, normally, that the one and the other is given a global value, but usually sticks to specific social spaces and especially adjusted to their genuine characteristics. The idea is, therefore, to adopt a dual position, that is, to assume duality without sacrificing any of the two extremes. Betting on the potential for convergence requires the proposal of multi-methodological or mixed methodological strategies that converge in a compromise between the quantitative and qualitative orientations of research.

Three multi-method integration strategies are proposed (Bericat Alastuey 1999): complementarity, combination and triangulation (Fig. 1).

Complementarity refers to integration strategies that incorporate a double and differentiated view of the facts, quantitative and qualitative, where one completes the vision of the other, without overlapping; represents the minimum degree of integration of methods. The final product of this type of multi-method design is usually a report with two well differentiated parts, each of which exposes the results achieved by the application of the respective method.

The combination subsidiary integrates one method into another, with the intention of strengthening the conclusions generated by the one considered as principal. It is not based, therefore, on the independence of methods as on complementarity. This is the way it is used when the discussion group is used to improve the preparation of a questionnaire or when the survey is used to generalize the obtained results in a research process supported in the discussion group.

Finally, triangulation represents the maximum degree of integration, since what is involved is the recognition by the two approaches of the same aspect of social reality. In this strategy what is intended is the convergence or overlapping of the results. The methods 
Fig. 1 Basic integration strategies. Source: Based on Bericat Alastuey (1999)

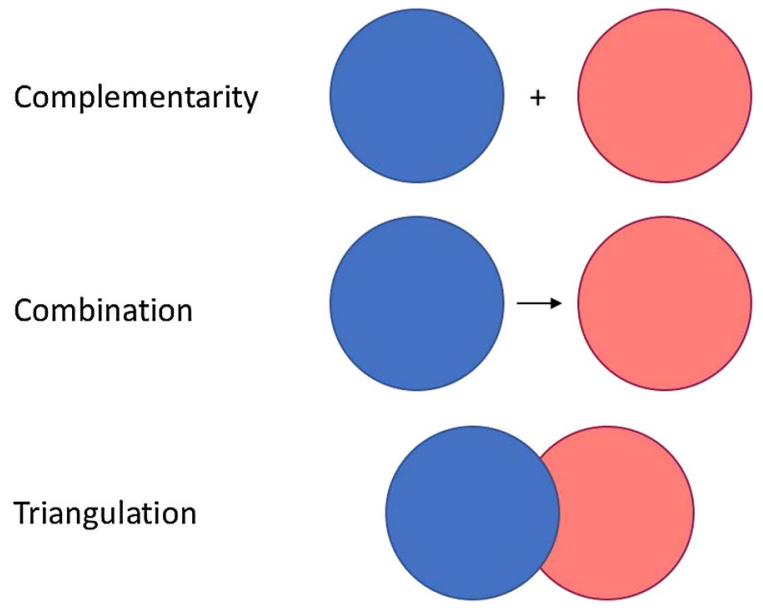

are applied independently, but the objective is to examine the level of convergence or divergence of the results.

Depending on the weight of each type of approach in the study, different positions are established in the qualitative-quantitative continuum (gradual combination) giving rise to different designs (Delgado 2014), as it is presented in Fig. 2.

Thus, when used together, the formal rigidity of the QUAN and the creativity and flexibility of the QUAL are combined; it is not a juxtaposition, but a mouldable combination in phases of the investigation of the QUAN/QUAL components; the collection and analysis
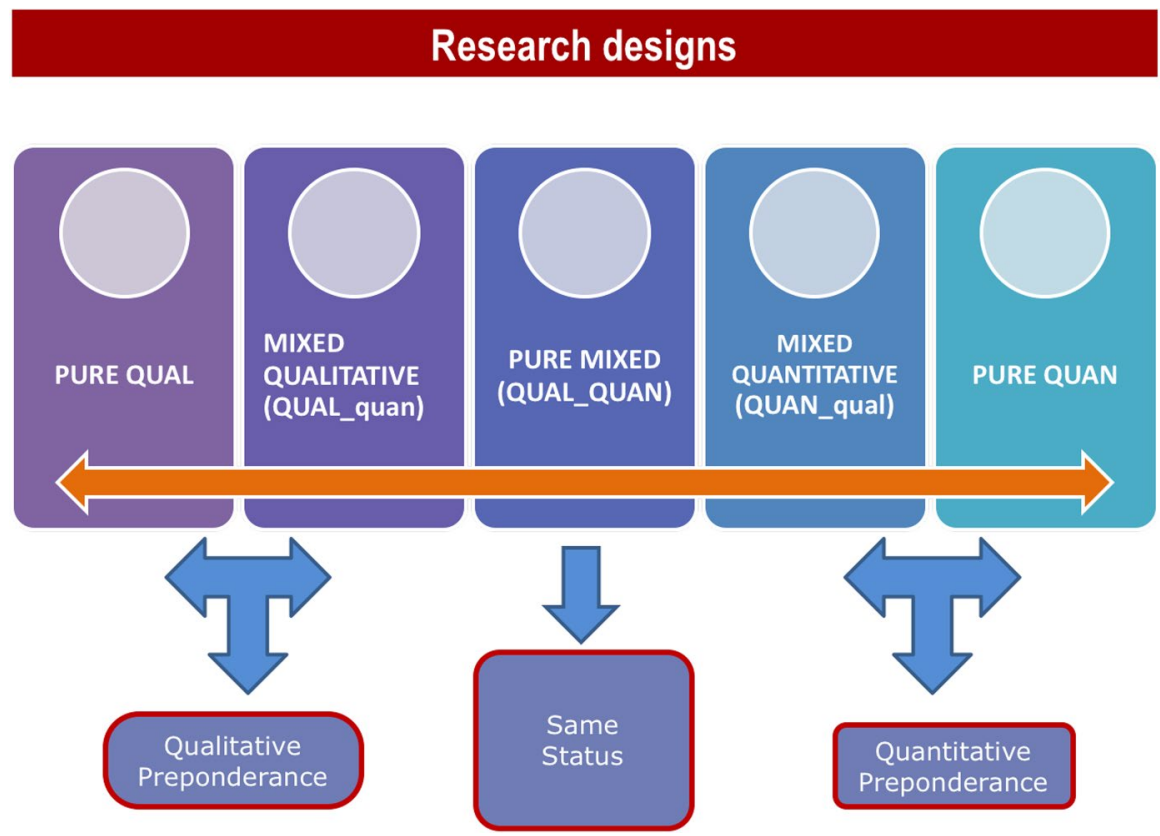

Fig. 2 Research designs. Source: Adapted by Delgado (2014) 
QUAN/QUAL are intended to integrate results and make a joint discussion that allows inferences to better understand and have a broader view of the studied phenomenon.

Several authors gather reflections made by experts and show that mixed methods research has expanded in recent decades with many publications.

Mertens et al. (2016) remember that when experience is developed in the use of methods where researchers feel comfortable, it is difficult to break with inertia. But by extending and refining methodological skills, it is possible to increase conceptual thinking, to see new ways of answering research questions, and even to identify questions that would not otherwise have occurred (Edwards 2008).

In this aspect, mixed methods may play a key role because they combine an integrate quantitative and qualitative methods allowing the researchers develop a wider set of research skills. Tashakkori and Teddlie (2003) indicate that mixed studies can be more enriching than the other approaches, since they can answer research questions that other methodologies cannot. In conclusion, some questions cannot necessarily be categorized as quantitative, qualitative or mixed.

The advancement of mixed models has also been possible due to the abandonment of radical methodological positions, the increase in scientific production, recognition of researchers using both perspectives, increased communication between sciences and disciplines, variety of new QUAL/QUAN instruments and for the evolution of new hardware and software technologies.

Progress in the mixed models leads to consider them as a different methodological approach (Johnson et al. 2007). Creswell and Plano Clark (2007) defined the mixed models as a research design with philosophical assumptions and their own research methods. These authors start from the idea that the use of quantitative and qualitative approaches, in combination, provides a better understanding of research problems than any separate approach.

During the decades of evolution of the mixed methods, researchers have tried to arrive at a consensus definition, although some of them have been against this proposal because they consider these methods as inappropriate (Bergman 2011). Tashakkori and Teddlie (1998) proposed the term mixed methodology for the first time. Johnson et al. (2007) reviewed 19 definitions, but found no uniformity. The plurality of the statements is aggravated because there are numerous types or taxonomies of mixed methods designs, proposed by different authors, and because the research purposes and questions are infinitely variable.

Since Greene et al. (1989) attempted to classify for the first time the designs used in different studies, many authors, including Creswell and Plano Clark (2011), Morse and Niehaus (2009), Nastasi et al. (2010), Mertens (2015) and Teddlie and Tashakkori (2009), have developed classifications of mixed method designs within an inclusive framework, as it is presented in Fig. 3.

Despite this lack of agreement, Mertens et al. (2016) affirm that minimum criteria must be agreed in order to justify the distinctive character and the construction of mixed methods identities. They recognize that there is a long simplistic tradition of emphasizing that mixed methods consist of combining qualitative and quantitative methods, so they point out that the important thing when defining mixed methods is to have two basic criteria: (1) In the mixed methods are involved more than one method, methodology, approach, theoretical or paradigmatic framework; and (2) mixed methods integrate the results of the different methods.

Really, each mixed study involves a unique work and its own design, which makes it a more "artisanal" task than the qualitative designs themselves; however, general design models have been identified that combine quantitative and qualitative methods, 


\section{Mixed designs}

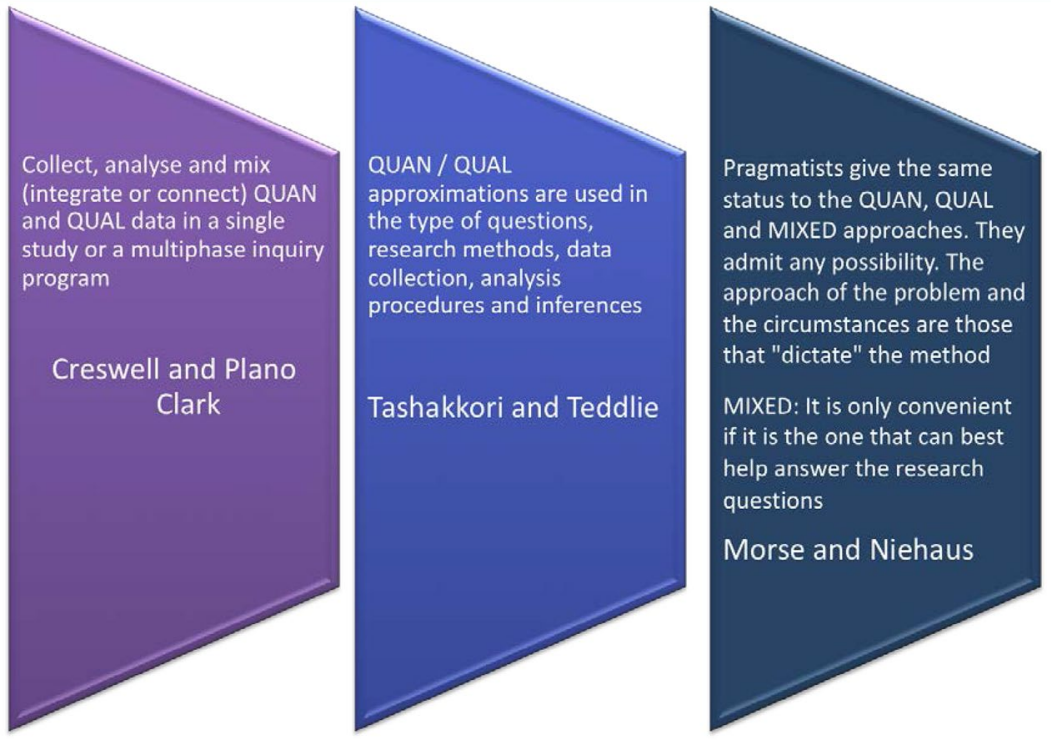

Fig. 3 Mixed designs

and that guide the construction and development of the particular design. Thus, the researcher chooses a general mixed design and then develops a specific design for its study (Hernández Sampieri et al. 2014).

The general mixed designs may be classified in (see Fig. 4):

- Concurrent ( simultaneously) If both methods are applied simultaneously or in parallel (quantitative and qualitative data are collected and analysed more or less at the same time).

- Sequential In a first phase, quantitative or qualitative data are collected and analysed, while in the second, data from the other method are collected and analysed. Normally, when the qualitative ones are obtained first, the intention is to explore a group of participants in their context and, later, the study is increased to a larger sample in order to generalize to the population (Creswell 2013).

- Conversion or transformation It consists of transforming data for its analysis, that is, it supposes that one type of data is converted into another (qualitative in quantitative or quantitative data in qualitative data) and then both sets of data are analysed under analysis both QUAN and QUAL (Teddlie and Tashakkori 2009; Bazeley 2010).

- Integration The combination between quantitative and qualitative methods can be given at several levels. In some situations, the mix can go as far as incorporating both approaches throughout the research process. These represent the highest degree of combination because the two approaches are intermingled throughout the process or in most stages. The investigation oscillates between the inductive and deductive schemes (Hernández-Sampieri and Mendoza 2008). 


\section{General mixed designs}

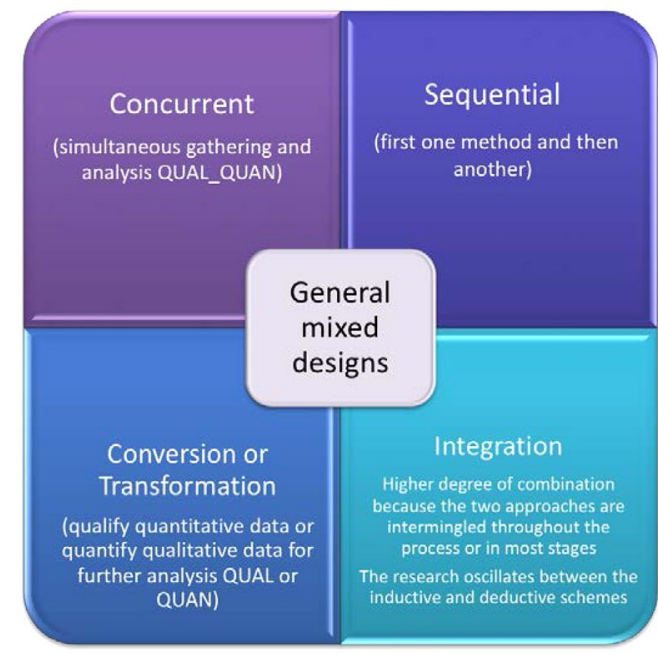

Fig. 4 General mixed designs

\section{Special issue contents}

This special issue comprises seven papers. The first one is entitled "Gender as a Moderator of the Relationship between Facebook ${ }^{\circledR}$ Addiction and Self-Efficacy for Learning in a College Sample: The Mediating Effect of Deliberative Belief' by Chun-wen Lin, which presents a study devoted to explore the mediating role of deliberative belief and the moderating role of gender on the relationships between Facebook ${ }^{\circledR}$ addiction and self-efficacy for learning among 690 college students. The results of this study revealed that high Facebook $^{\circledR}$ addiction was associated with decreased deliberative belief, which was further associated with decreased self-efficacy for learning. Moreover, Facebook ${ }^{\circledR}$ addiction tends to significantly reduce the self-efficacy for learning for male students but not for female students.

In the second paper, entitled "Building, coding and programming 3D models Via a Visual Programming Environment", Pinto-Llorente et al. explore the computational thinking approach (Wing 2006; García-Peñalvo 2016) in Spanish pre-university studies (LlorensLargo et al. 2017; Velázquez-Iturbide et al. 2018). The study found that the project developed was effective to help students to achieve the learning objectives of the unit, and also to begin building, coding and programming 3D models. The research showed the teacher' fundamental role as a guide and students' active role as builders, programmers, or presenters. There were evidences of the possibilities offered to acquire the skills of critical thinking, creative thinking, problem solving, reflection, collaboration, communication, and time management. Based on the evidences of this study, authors recommend the incorporation of computational thinking in pre-university education, especially in primary education.

The third paper, by Keleszade et al., is entitled "The effectiveness of technology-assisted history teaching based on peace training: The case of history of Cyprus". It presents a embedded design mixed method, in which first qualitative data were obtained through content analysis and quantitative data were evaluated with the Wilcoxon signed-rank test, 
specifically in this research the quantitative method was dominant (experimental study) and that the qualitative method (interviews and observations) supported the quantitative method. Researcher observations show that the awareness of students for peace education increased and their historical empathy and cooperative working skills were developed. However, despite such positive results, it was also discovered that there is no significant difference in quantitative terms in the attitude of students towards the history of Cyprus.

The fourth paper is entitled "Investigation of the level of consciousness of citizens about the climate change", by Fidan Aslanova. It presents a research devoted to investigate the consciousness level of native people living in different regions of Libya on climate issue, finding significant differences about age, gender and education variables, and the people of Libya participating in the survey have been informed about climate change.

The fifth paper is entitled "Nursing Staff Intentions to Continuously Use a Blended E-Learning System from an Integrative Perspective", by Tsai et al. It is devoted to investigate the factors affecting nurses' behavioural intentions of using a blended e-learning system (Gros and García-Peñalvo 2016). Authors synthesized the technology acceptance model, the information system success model, and perceived enjoyment into a hypothesized model to discuss and predict nurses' intentions of using the b-learning system continuously.

The sixth paper, by Sánchez-Gómez et al. and entitled "Software as a facilitator of quality processes in social sciences research", is devoted to evaluate the strategy of triangulation in the validation of information by integrating quantitative/qualitative information based on the use of different statistics software packages. The results confirm the benefit of using data-processing software as a resource to facilitate multimethod strategies in educational research owing to its strengthening of results and the examination of the level of convergence or divergences within them.

The last paper is entitled "The Role of Empathy between Functional Competence Diversity and competence Acquisition-A Case Study of Interdisciplinary Teams”, by Lin and Chuang. In this paper, authors perform a study intended to verity the relationships among team functional competence diversity, empathy, and competence acquisition and placed more focus on team learning rather than on individual lecturing. This study suggests that when team members have greater empathy competence, it reduces arguments, helps polish interpersonal skills, and facilitates tight cooperation that leads to the acquisition of heterogeneous knowledge and the development of systematic curricula.

Acknowledgements This work has been partially funded by the Spanish Government Ministry of Economy and Competitiveness throughout the DEFINES Project (Ref. TIN2016-80172-R) and the Ministry of Education of the Junta de Castilla y León (Spain) throughout the T-CUIDA Project (Ref. SA061P17).

\section{References}

Bazeley, P.: Computer-assisted integration of mixed methods data sources and analyses. In: Tashakkori, A., Teddlie, C. (eds.) Sage Handbook of Mixed Methods in Social and Behavioral Research, pp. 431-467. SAGE, Thousand Oaks (2010)

Bergman, M.M.: The good, the bad, and the ugly in mixed methods research and design. J. Mixed Methods Res. 5, 271-275 (2011)

Bericat Alastuey, E.: La integración de los métodos cuantitativo y cualitativo en la investigación social. Significado y medida. Ariel, Barcelona (1999)

Bruyn, S.T.H.: The Human Perspective in Sociology: The Methodology of Participant Observation. PrenticeHall, Englewood Cliffs (1966)

Cohen, L., Manion, L., Morrison, K.: Research Methods in Education, 8th edn. Routledge, Milton, Oxfordshire (2018)

Creswell, J.W.: Research Design: Qualitative, Quantitative, and Mixed Methods Approaches, 4th edn. SAGE, Thousand Oaks (2013) 
Creswell, J.W., Plano Clark, V.L.: Designing and Conducting Mixed Methods Research. SAGE, Thousand Oaks (2007)

Creswell, J.W., Plano Clark, V.L.: Designing and Conducting Mixed Methods Research, 2nd edn. SAGE, Thousand Oaks (2011)

Delgado, C.: Viajando a Ítaca por los mares cuantitativos, manual de ruta para investigar en grado y en postgrado. Amaru, Salamanca (2014)

Durkheim, E.: Rules of Sociological Method. The Free Press, New York (1982)

Edwards, J.R.: To prosper, organizational psychology should ... overcome methodological barriers to progress. J. Organ. Behav. 29, 469-491 (2008)

Eliaeson, S.: Max Weber's methodology: an ideal-type. J. Hist. Behav. Sci. 36, 241-263 (2000)

García-Peñalvo, F.J.: What computational thinking is. J. Inf. Technol. Res. 9(3), v-viii (2016)

García-Peñalvo, F.J., Seoane-Pardo, A.M.: Una revisión actualizada del concepto de eLearning. Décimo Aniversario. Educ. Knowl. Soc. 16(1), 119-144 (2015)

Greene, J.C., Caracelli, V.J., Graham, W.F.: Toward a conceptual framework for mixed-method evaluation designs. Educ. Eval. Policy Anal. 11, 255-274 (1989)

Gros, B., García-Peñalvo, F.J.: Future trends in the design strategies and technological affordances of e-learning. In: Spector, M., Lockee, B.B., Childress, M.D. (eds.) Learning, Design, and Technology. An International Compendium of Theory, Research, Practice, and Policy, pp. 1-23. Springer, Basel (2016)

Hernández-Sampieri, R., Mendoza, C.P.: El matrimonio cuantitativo-cualitativo: El paradigma mixto. In Proc. 6to. Congreso de Investigación en Sexología, Villahermosa, Tabasco, México (2008)

Hernández Sampieri, R., Fernández Collado, C., Baptista Lucio, P.: Metodología de la investigación, 6th edn. McGraw-Hill, México (2014)

Johnson, R.B., Onwuegbuzie, A.J., Turner, L.A.: Toward a definition of mixed methods research. J. Mixed Methods Res. 1, 112-133 (2007)

Llorens-Largo, F., García-Peñalvo, F.J., Molero Prieto, X., Vendrell Vidal, E.: La enseñanza de la informática, la programación y el pensamiento computacional en los estudios preuniversitarios. Educ. Knowl. Soc. 18(2), 7-17 (2017). https://doi.org/10.14201/eks2017182717

Mertens, D.M.: Research and Evaluation in Education and Psychology: Integrating Diversity with Quantitative, Qualitative, and Mixed Methods, 4th edn. Sage Publications, Thousand Oaks (2015)

Mertens, D.M., Bazeley, P., Bowleg, L., Fielding, N., Maxwell, J., Molina-Azorin, J.F., Niglas, K.: The future of mixed methods: a five year projection to 2020. https://goo.gl/UDkg1W (2016). Accessed 12 Aug 2018

Morse, J.M., Niehaus, L.: Mixed Method Design: Principles and Procedures. Left Coast Press Inc., Walnut Creek (2009)

Nastasi, B.K., Hitchcock, J.H., Brown, L.M.: An inclusive framework for conceptualizing mixed methods design typologies: moving toward fully integrated synergistic research models. In: Tashakkori, A., Teddlie, C. (eds.) Sage Handbook of Mixed Methods in Social and Behavioral Research, pp. 305-338. SAGE, Thousand Oaks (2010)

Sánchez-Prieto, J.C., Olmos-Migueláñez, S., García-Peñalvo, F.J.: Informal tools in formal contexts: development of a model to assess the acceptance of mobile technologies among teachers. Comput. Hum. Behav. 55A, 519-528 (2016)

Sánchez-Prieto, J.C., Olmos-Migueláñez, S., García-Peñalvo, F.J.: MLearning and pre-service teachers: an assessment of the behavioral intention using an expanded TAM model. Comput. Hum. Behav. 72, 644654 (2017)

Tashakkori, A., Teddlie, C.: Mixed Methodology: Combining Qualitative and Quantitative Approaches. SAGE, Thousand Oaks (1998)

Tashakkori, A., Teddlie, C.: The past and future of mixed methods research: from data triangulation to mixed model designs. In: Tashakkori, A., Teddlie, C. (eds.) Handbook on Mixed Methods in the Behavioral and Social Sciences, pp. 671-702. SAGE, Thousand Oaks (2003)

Teddlie, C., Tashakkori, A.: Foundations of Mixed Methods Research: Integrating Quantitative and Qualitative Approaches in the Social and Behavioral Sciences. SAGE, Thousand Oaks (2009)

Velázquez-Iturbide, J.Á., Bahamonde, A., Dabic, S., Escalona, M.J., Feito, F., Fernández Cabaleiro, S., Ferrero Martín, B., Garay Vitoria, N., García, J.C., García Borgoñón, L., García Martínez, M., García Molina, J., García Varea, I., Hermenegildo Salinas, M., Larraza Mendiluze, E., Llorens Largo, F., Mateos, J.A., Moratel Muñoz, A., Mozos, D., Pimentel, E., Sahelices, B., Toro, M., Zapata Ros, M.: Informe del Grupo de Trabajo SCIE/CODDII sobre la enseñanza preuniversitaria de la informática. In: Sociedad Científica Informática de España, Conferencia de Decanos y Directores de Ingeniería Informática, Spain, https://goo. gl/dmCPgm (2018). Accessed 12 Aug 2018

Wing, J.M.: Computational thinking. Commun. ACM 49, 33-35 (2006) 